\title{
The genetic basis of hyaline fibromatosis syndrome in patients from a consanguineous background: a case series
}

Leila Youssefian ${ }^{1,4+}$, Hassan Vahidnezhad ${ }^{1,2+}$, Andrew Touati ${ }^{1,3 \dagger}$, Vahid Ziaee ${ }^{5+}$, Amir Hossein Saeidian 1 , Sara Pajouhanfar ${ }^{1}$, Sirous Zeinali ${ }^{2,6}$ and Jouni Uitto ${ }^{1 *}$ (D)

\begin{abstract}
Background: Hyaline fibromatosis syndrome (HFS) is a rare heritable multi-systemic disorder with significant dermatologic manifestations. It is caused by mutations in ANTXR2, which encodes a transmembrane receptor involved in collagen VI regulation in the extracellular matrix. Over 40 mutations in the ANTXR2 gene have been associated with cases of HFS. Variable severity of the disorder in different patients has been proposed to be related to the specific mutations in these patients and their location within the gene.

Case presentation: In this report, we describe four cases of HFS from consanguineous backgrounds. Genetic analysis identified a novel homozygous frameshift deletion c.969del (p.lle323Metfs*14) in one case, the previously reported mutation c.134 T>C (p.Leu45Pro) in another case, and the recurrent homozygous frameshift mutation c.1073dup (p.Ala359Cysfs*13) in two cases. The epidemiology of this latter mutation is of particular interest, as it is a candidate for inhibition of nonsense-mediated mRNA decay. Haplotype analysis was performed to determine the origin of this mutation in this consanguineous cohort, which suggested that it may develop sporadically in different populations.
\end{abstract}

Conclusions: This information provides insights on genotype-phenotype correlations, identifies a previously unreported mutation in ANTXR2, and improves the understanding of a recurrent mutation in HFS.

Keywords: Hyaline fibromatosis syndrome, Genodermatoses, Mutation analysis, HFS, ANTXR2 gene

\section{Background}

Hyaline fibromatosis syndrome (HFS, OMIM\# 228600) is a rare heritable disorder with variable severity and frequent lethality, characterized by thickened skin with nodules, papules and plaques, often with a periorificial and perianal distribution, gingival hypertrophy, and joint contractures. Osteopenia, predisposition to respiratory infections, and diarrhea are often present.

HFS is an autosomal recessive disorder, caused by mutations in the ANTXR2 gene, also referred to as CMG2. This gene encodes ANTXR2, a type I transmembrane protein initially characterized for its role in angiogenesis

\footnotetext{
* Correspondence: Jouni.Uitto@jefferson.edu

${ }^{\dagger}$ Equal contributors

'Department of Dermatology and Cutaneous Biology, Sidney Kimmel Medical College, Thomas Jefferson University, 233 S. 10th Street, Suite 450 BLSB, Philadelphia, PA 19107, USA

Full list of author information is available at the end of the article
}

and as a receptor for the anthrax toxin [1,2]. While over 40 mutations in the ANTXR2 gene have been reported in association with HFS so far, most of them $(\sim 70 \%)$ being missense and frameshift mutations scattered along the protein, the molecular pathogenesis of this disease has only recently begun to be understood. Specifically, ANTXR2 has been shown to act as a receptor for collagen VI, promoting lysosome-mediated degradation of collagen VI in the extracellular matrix [3], consistent with the finding that patients with HFS develop an accumulation of collagen VI [4]. Thus, defective collagen VI degradation due to nonfunctional ANTXR2 likely leads to collagen accumulation in patients' tissues, resulting in the clinical manifestations of HFS.

In this report, we examine four patients from consanguineous Iranian backgrounds diagnosed with HFS, and present their clinical and genetic findings (Table 1). 
Table 1 Clinical and genetic findings in four patients with HFS

\begin{tabular}{|c|c|c|c|c|}
\hline & Case 1 & Case 2 & Case 3 & Case 4 \\
\hline $\begin{array}{l}\text { Mutation in the } \\
\text { ANTXR2 gene }\end{array}$ & $\begin{array}{l}\text { c.969del } \\
\text { (p.lle323Metfs*14) }\end{array}$ & $\begin{array}{l}\text { c.134 T > C } \\
\text { (p.Leu45Pro) }\end{array}$ & $\begin{array}{l}\text { c.1073dup } \\
\text { (p.Ala359Cysfs*13) }\end{array}$ & $\begin{array}{l}\text { c.1073dup } \\
\text { (p.Ala359Cysfs*13) }\end{array}$ \\
\hline $\begin{array}{l}\text { Parental } \\
\text { consanguinity }\end{array}$ & First cousin & First cousin & $\begin{array}{l}\text { First cousin, } \\
\text { once removed }\end{array}$ & First cousin \\
\hline Status & $\begin{array}{l}\text { Deceased } \\
(6 \text { months })\end{array}$ & $\begin{array}{l}\text { Deceased } \\
\text { (10 months) }\end{array}$ & $\begin{array}{l}\text { Alive } \\
\text { ( } 2 \text { years old) }\end{array}$ & $\begin{array}{l}\text { Deceased } \\
\text { (1.5 years) }\end{array}$ \\
\hline Age of onset & 3 months & 1 month & Birth & Birth \\
\hline Skin findings & $\begin{array}{l}\text { Erythematous plaques on } \\
\text { torso, hyperpigmentation, } \\
\text { skin thickening }\end{array}$ & $\begin{array}{l}\text { Perianal plaques, } \\
\text { hyperpigmentation, } \\
\text { skin thickening }\end{array}$ & $\begin{array}{l}\text { Papular lesions on forehead, ears, } \\
\text { and around the nose, hyperpigmentation, skin } \\
\text { thickening }\end{array}$ & $\begin{array}{l}\text { Perianal plaques, perioral } \\
\text { papules, hyperpigmentation, } \\
\text { skin thickening }\end{array}$ \\
\hline $\begin{array}{l}\text { Joint contractures/ } \\
\text { pain }\end{array}$ & + & + & + & + \\
\hline Low bone density & + & - & - & - \\
\hline Gingival hypertrophy & + & + & + & + \\
\hline Recurrent diarrhea & + & + & - & + \\
\hline Respiratory infections & + & + & + & + \\
\hline
\end{tabular}

\section{Case presentation}

Case 1 presented in infancy with dusky, erythematous plaques and hyperpigmentation over the torso and joints (Fig. 1a). Painful joint contractures, recurrent diarrhea, gingival hypertrophy, and recalcitrant upper respiratory tract infections were present. The patient died from infectious complications at 6 months of age.

Case 2 presented at 1 month of age with joint contractures, skin thickening, hyperpigmentation, and perianal plaques (Fig. 1b). The patient died at 10 months of age following recurrent respiratory infections and severe diarrhea.

Case 3 presented neonatally with painful contractures of the lower extremities (Fig. 1c). The patient developed papular lesions on the forehead, nose and ears, as well as hyperpigmentation over the medial malleoli. Gingival hyperplasia was present, and the patient developed frequent respiratory infections.

Case 4 presented in infancy with painful contractures of the legs and interphalangeal joints, perianal erythematous plaques, and perioral papules (Fig. 1d). Additional features included hyperpigmentation over the medial malleoli, gingival hypertrophy, recurrent diarrhea, and respiratory infections. The patient died at 18 months of age from infectious complications. On the basis of clinical presentations, HFS was suspected in all four cases.

Genetic analysis of DNA isolated from peripheral blood of each proband was performed using PCR-based amplification using 17 pairs of primers spanning all exons and $\sim 50$ bp of flanking intronic sequences of the ANTXR2 gene (NM_058172; primer sequences available upon request). PCR products were bidirectionally sequenced using an automated sequencer (3730; Applied Biosystems, Foster City, CA, USA). Sequencing revealed a previously unreported homozygous frameshift deletion mutation c.969del (p.Ile323Metfs"14) in exon 12 in Case 1 , and the previously reported homozygous missense mutation c.134 $\mathrm{T}>\mathrm{C}$ (p.Leu45Pro) in exon 1 in Case 2 [5]. A homozygous frameshift insertion c.1073dup (p. Ala359Cysfs*13) in exon 13 was identified in Cases 3 and 4. This mutation has been identified in several previous cases of HFS, including an Iranian case reported by our laboratory [6]. The mutation occurs in a cytosine/guanosine rich region of DNA that has been suggested to be prone to mutational events including insertions and deletions $[7,8]$.

To determine whether this c.1073dup (p.Ala359Cysfs*13) mutation was due to independent mutational events at this hotspot, or due to a single distant founder effect mutation in the Iranian population, haplotype analysis was performed using a series of informative single nucleotide polymorphisms (SNPs) around the ANTXR2 gene (Table 2). HapMap data (https://snpinfo.niehs.nih. gov/snpinfo/snptag.html) were used to choose tag SNPs, spanning a region of $2.91 \mathrm{Mb}$ encompassing the ANXTR2 gene. Selected tag SNPs were rs4692955, rs1493177, rs12509909, rs10011562, rs7685006, rs4975133, rs4975132, and rs4975131 (https://www.ncbi.nlm.nih.gov/SNP). Five intragenic SNPs in ANTXR2 were additionally included as tag SNPs: rs13140055, rs4594664, rs11730210, rs4336166, and rs12647691 (https://www.ncbi.nlm.nih.gov/SNP). Overall, 13 SNPs were genotyped by PCR (primer sequences available upon request) and bidirectionally sequenced using an automated sequencer (3730; Applied Biosystems).

Haplotype analysis was performed in Cases 3 and 4, as well as in our previously reported Iranian case of HFS with the same c.1073dup (p.Ala359Cysfs*13) mutation [6] (Table 2). Comparison of the haplotypes of these 


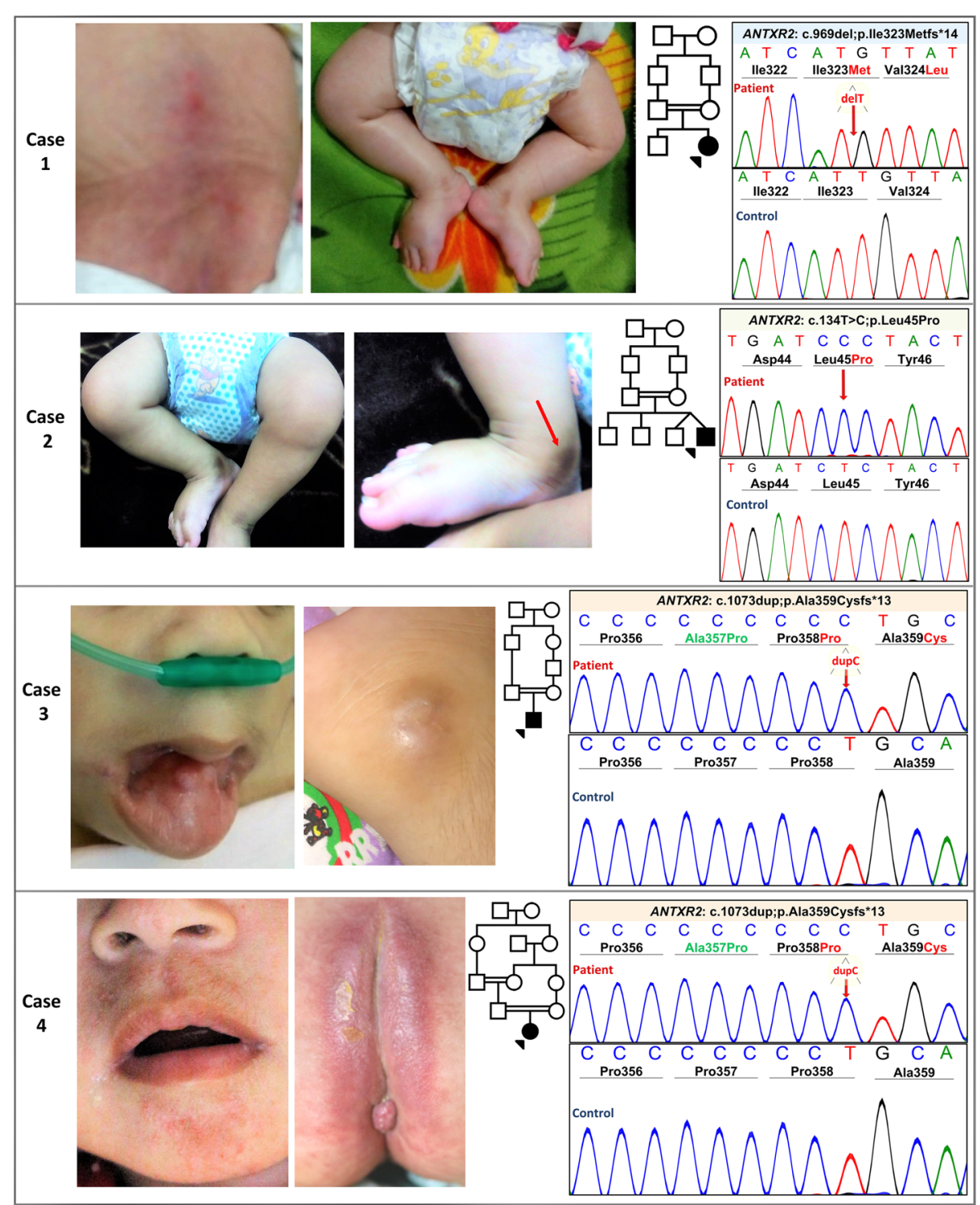

Fig. 1 Clinical and genetic findings in four cases of HFS. Pedigrees displaying consanguinity, clinical findings, and Sanger sequencing of the identified ANTXR2 mutations. In each case, the upper sequence panel represents the mutant allele, as compared to reference sequence in a healthy control below. a Clinical features of Case 1 included erythematous plaques, hyperpigmentation, and joint contractures of the lower extremities. Sanger sequencing identified a novel homozygous mutation, c.969del, which is predicted to result in truncated protein product, p.lle323Metfs*14. b First cousin consanguinity, lower extremity contractures with hyperpigmentation over the medial malleolus, and Sanger sequencing of the c.134C > T (p.Leu45Pro) mutation in Case 2. c Case 3 developed flesh-colored papules on the face, including periauricular lesions, as well as gingival hyperplasia. Sequencing revealed the recurrent mutation c.1073dup (p.Ala359Cysfs*13). d Case 4 presented with characteristic perianal lesions and perioral papules. The same mutation as in Case 3 was identified by Sanger sequencing. The green in Case 3 and 4 represents the amino acid change, p.Ala357Pro, resulting from a common benign polymorphism, C.1069G > C (rs12647691)

three Iranian patients showed a lack of haplotype conservation for SNPs in this region.

\section{Discussion and conclusions}

Collectively, these cases add to the genetic understanding of HFS. Cases with mutations in the exons encoding the cytoplasmic tail of ANTXR2 protein have been reported to be clinically less severe than those with mutations upstream in the gene, which is likely to be due to the role of the cytoplasmic tail in receptor turnover, rather than directly in ligand-binding [9]. While Cases 3 and 4 harbored truncating mutations affecting the cytoplasmic tail, the upstream frameshift mutation in Case 1 is predicted to result in a truncated protein, likely impairing receptor stability in the cellular membrane. Case 2 harbored a mutation in the von Willebrand domain, essential for ligand binding, including to collagen VI [3]. Case 1 and 2 had the most severe phenotypes 
Table 2 Haplotype analysis in cases with the c.1073dup mutation in ANTXR2 gene

\begin{tabular}{|c|c|c|c|c|c|c|c|c|c|c|c|c|c|}
\hline SNP & 1 & 2 & 3 & 4 & 5 & 6 & 7 & 8 & 9 & 10 & 11 & 12 & 13 \\
\hline SNP ID & 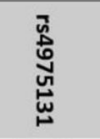 & 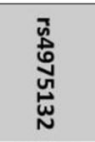 & 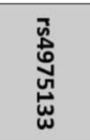 & 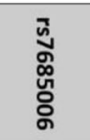 & 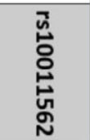 & 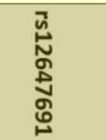 & 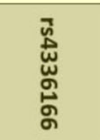 & 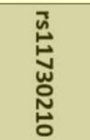 & 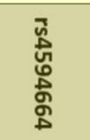 & 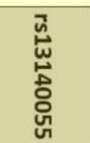 & 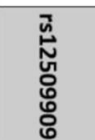 & 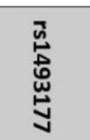 & 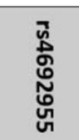 \\
\hline $\begin{array}{l}\text { Chr. Location } \\
\text { Chr4: (on Assembly GRCh38) }\end{array}$ & $\begin{array}{c}78.499 \\
\mathrm{Mb}\end{array}$ & $\begin{array}{c}78.499 \\
\mathrm{Mb}\end{array}$ & $\begin{array}{c}78.499 \\
\mathrm{Mb}\end{array}$ & $\begin{array}{c}79.473 \\
\mathrm{Mb}\end{array}$ & $\begin{array}{c}79.878 \\
\mathrm{Mb}\end{array}$ & $\begin{array}{c}79.984 \\
\text { Mb } \\
\text { Exon } 13\end{array}$ & $\begin{array}{c}80.081 \\
\mathrm{Mb} \\
\text { Intron } 11\end{array}$ & $\begin{array}{c}80.055 \\
\text { Mb } \\
\text { Intron } 5\end{array}$ & $\begin{array}{c}80.055 \\
\text { Mb } \\
\text { Intron } 4\end{array}$ & $\begin{array}{c}80.072 \\
\text { Mb } \\
5-\text { UTR }\end{array}$ & $\begin{array}{c}80.153 \\
\mathrm{Mb}\end{array}$ & $\begin{array}{c}80.746 \\
\mathrm{Mb}\end{array}$ & $\begin{array}{c}81.417 \\
\mathrm{Mb}\end{array}$ \\
\hline MAF & $.41(\mathrm{~A})$ & $.41(\mathrm{~A})$ & .31 (C) & .45 (C) & $.48(\mathrm{~A})$ & $.30(A)$ & .29 (A) & $.36(A)$ & $.30(A)$ & $.38(A)$ & $.41(\mathrm{G})$ & $.48(A)$ & $.44(T)$ \\
\hline Case 3 & A & G & $\mathbf{T}$ & C & G & C & G & A & C & A & G & G & $\mathbf{T}$ \\
\hline Case 4 & A & G & $\mathbf{T}$ & C & A & C & A & C & A & A & A & A & C \\
\hline Prior case & $\mathbf{T}$ & A & C & C & $\mathbf{A}$ & C & A & A & C & A & A & A & $\mathbf{T}$ \\
\hline
\end{tabular}

Haplotype analysis was performed in three cases of HFS homozygous for the c.1073dup (p.Ala359Cysfs*13) mutation in ANTXR2, including Case 3 and Case 4 from the present report, and a previously reported patient of Iranian descent with the identical mutation. Thirteen informative single nucleotide polymorphisms (SNPs) with minor allele frequencies (MAF) ranging from 0.29 to 0.48 in a $2.91 \mathrm{Mb}$ region of chromosome 4 (https://www.ncbi.nlm.nih.gov/SNP) were sequenced in each case, including five SNPs within the ANTXR2 gene (nos. 6-10, yellow highlight). The position of the c.1073dup mutation is indicated by a red asterisk. Analysis revealed that while each patient was homozygous for the allele of each included SNP as expected in consanguineous families, the SNP haplotype differed between these three cases. These data suggest an independent origin of this mutation event rather than being inherited from a common ancestor

and earliest lethality, supporting the notion that mutations upstream of the cytoplasmic tail domain result in increased phenotypic severity.

The consequences of specific frameshift mutations in the ANTXR2 gene have previously been examined, including the c.1073dup (p.Ala359Cysfs"13) mutation disclosed in Cases 3 and 4 [10]. Patients who are homozygous for this mutation have ANTXR2 mRNA expression levels that are half of those found in normal individuals [11]. However, the protein product of this mutated form of ANTXR2 has been shown to reach the cell membrane with partial functionality [10]. Thus, this mutation is a candidate for targeted inhibition of nonsense-mediated mRNA decay. The c.1073dup (p. Ala359Cysfs*13) mutation has been reported multiple times previously, and understanding the inheritance and epidemiology of this mutation in different populations is important in determining which HFS patients would benefit from potential therapy. While this mutation could be expected to have developed in isolated mutational events in most cases, we sought to determine the inheritance pattern of this mutation in a highly consanguineous population of Iran, in which inheritance of recurrent mutations causing recessive diseases is often due to transmission of a mutated haplotype from a common ancestor through generations, i.e., the founder effect. The haplotype analysis of our three patients showed that the haplotypes harboring this mutation are identical by state, but not by descent, which supports the notion that this mutation is not the result of a founder effect in this Iranian cohort. Consequently, this mutation may occur sporadically in different populations, and therapeutic approaches targeting this mutation would likely have benefits in any population affected by HFS.

This study reports a novel causative mutation in HFS, contributes to our understanding of genotype-phenotype correlations for this syndrome, and improves our understanding of a recurrent ANTXR2 gene mutation that may be a candidate for targeted therapy.

\section{Abbreviations}

HFS: Hyaline fibromatosis syndrome; MAF: Minor allele frequencies; SNPs: Single nucleotide polymorphisms

\section{Acknowledgements}

We thank the patients and their families for participation. Carol Kelly assisted in manuscript preparation.

\section{Funding}

Thomas Jefferson University, Department of Dermatology and Cutaneous Biology.

Availability of data and materials

Data is available, including primer sequences generated, from the corresponding author upon request.

\section{Authors' contributions}

LY performed genetic testing, analyzed and interpreted patient data, and contributed to writing the manuscript. HV analyzed and interpreted patient data, and contributed to writing the manuscript. VZ provided clinical data, expertise, contributed to analysis and interpretation of the data, and drafting the manuscript. AT performed genetic testing, analyzed and interpreted patient data, and contributed to writing the manuscript. AHS performed genetic testing, analyzed and interpreted patient data, and contributed to writing the manuscript. SP performed genetic testing, analyzed and interpreted patient data. SZ provided genetic counseling and analysis of data. JU provided clinical and genetic expertise and oversaw the project. All authors read and approved the final manuscript.

Ethics approval and consent to participate

Patient sample collection was performed following approval by the Institutional Review Board of the Pasteur Institute of Iran, and all subjects as 
well as the parents of underage patients gave written informed consent to participate in research.

\section{Consent for publication}

Consent for publication was obtained from the parents of patients included in this study, including for individual details and images.

\section{Competing interests}

The authors declare that they have no competing interests.

\section{Publisher's Note}

Springer Nature remains neutral with regard to jurisdictional claims in published maps and institutional affiliations.

\section{Author details}

'Department of Dermatology and Cutaneous Biology, Sidney Kimmel Medical College, Thomas Jefferson University, 233 S. 10th Street, Suite 450 BLSB, Philadelphia, PA 19107, USA. ${ }^{2}$ Biotechnology Research Center, Department of Molecular Medicine, Pasteur Institute of Iran, Tehran, Iran. ${ }^{3}$ Drexel University College of Medicine, Philadelphia, PA, USA. ${ }^{4}$ Department of Medical Genetics, School of Medicine, Tehran University of Medical Sciences, Tehran, Iran. ${ }^{5}$ Department of Pediatrics, Children's Medical Center, Pediatrics Center of Excellence, Tehran, Iran. ${ }^{6}$ Kawsar Human Genetics Research Center, Tehran, Iran.

Received: 6 December 2017 Accepted: 19 April 2018

Published online: 25 May 2018

\section{References}

1. Bell SE, Mavila A, Salazar R, Bayless K, Kanagala S, Maxwell SA, et al. Differential gene expression during capillary morphogenesis in 3D collagen matrices: regulated expression of genes involved in basement membrane matrix assembly, cell cycle progression, cellular differentiation and G-protein signaling. J Cell Sci. 2001;114:2755-73.

2. Scobie HM, Rainey GJ, Bradley KA, Young JA. Human capillary morphogenesis protein 2 functions as an anthrax toxin receptor. Proc Nat Acad Sci U S A. 2003:100:5170-4.

3. Burgi J, Kunz B, Abrami L, Deuquet J, Piersigilli A, Scholl-Burgi S, et al. CMG2/ANTXR2 regulates extracellular collagen VI which accumulates in hyaline fibromatosis syndrome. Nat Commun. 2017;8:15861.

4. Tanaka K, Ebihara T, Kusubata M, Adachi E, Arai M, Kawaguchi N, et al, Abnormal collagen deposition in fibromas from patient with juvenile hyaline fibromatosis. J Dermatol Sci. 2009;55:197-200.

5. Hanks S, Adams S, Douglas J, Arbour L, Atherton DJ, Balci S, et al. Mutations in the gene encoding capillary morphogenesis protein 2 cause juvenile hyaline fibromatosis and infantile systemic hyalinosis. Am J Hum Genet. 2003;73:791-800

6. Youssefian L, Vahidnezhad H, Aghighi Y, Ziaee V, Zeinali S, Abiri M, et al. Hyaline fibromatosis syndrome: a novel mutation and recurrent founder mutation in the CMG2/ANTXR2 gene. Acta Derm Venereol. 2017:97:108-9.

7. El-Kamah GY, Fong K, El-Ruby M, Afifi HH, Clements SE, Lai-Cheong JE, et al. Spectrum of mutations in the ANTXR2 (CMG2) gene in infantile systemic hyalinosis and juvenile hyaline fibromatosis. Br J Dermatol. 2010;163:213-5.

8. Vahidnezhad H, Ziaee V, Youssefian L, Li Q, Sotoudeh S, Uitto J. Infantile systemic hyalinosis in an Iranian family with a mutation in the CMG2/ ANTXR2 gene. Clin Exp Dermatol. 2015;40:636-9.

9. Deuquet J, Lausch E, Superti-Furga A, van der Goot FG. The dark sides of capillary morphogenesis gene 2. EMBO J. 2012;31:3-13.

10. Yan SE, Lemmin T, Salvi S, Lausch E, Superti-Furga A, Rokicki D, et al. In-depth analysis of hyaline fibromatosis syndrome frameshift mutations at the same site reveal the necessity of personalized therapy. Hum Mutat. 2013;34:1005-17.

11. Deuquet J, Lausch E, Guex N, Abrami L, Salvi S, Lakkaraju A, et al. Hyaline fibromatosis syndrome inducing mutations in the ectodomain of anthrax toxin receptor 2 can be rescued by proteasome inhibitors. EMBO Mol Med. 2011:3:208-21.

\section{Ready to submit your research? Choose BMC and benefit from:}

- fast, convenient online submission

- thorough peer review by experienced researchers in your field

- rapid publication on acceptance

- support for research data, including large and complex data types

- gold Open Access which fosters wider collaboration and increased citations

- maximum visibility for your research: over $100 \mathrm{M}$ website views per year

At BMC, research is always in progress.

Learn more biomedcentral.com/submissions 